\title{
An assessment of the preregistration year experience
}

\author{
J E ELIZABETH, S HUGHES
}

\begin{abstract}
All 115 graduates qualifying at Liverpool University Medical School in one year were sent a questionnaire in the final week of their preregistration year to assess the experience they had gained.

Of the 105 graduates (92\%) who replied, $99(94 \%)$ considered the supervision that they had received to be adequate, $89(85 \%)$ received most of their teaching from other junior doctors, and only 47 believed that they had learnt a considerable amount from their consultant colleagues. Half of the doctors received little or no training in terminal care. Although $100(95 \%)$ felt competent in dealing with various medical emergencies, cardiopulmonary resuscitation skills were less developed; only $71(68 \%)$ were confident in using a defibrillator, and $37(35 \%)$ considered themselves to be competent in dealing with cardiac arrhythmias. A fifth of the doctors found interviewing relatives stressful. Of the 105 doctors who replied, $77(73 \%)$ thought that their preregistration experience had had little or no effect on their choice of career.
\end{abstract}

\section{Introduction}

The General Medical Council recommends that when graduates qualify they should have enough knowledge "to assume the responsibilities of a preregistration house officer" and have developed "the professional skills necessary to deal with common medical emergencies."' We report on a survey carried out among house officers to provide a subjective assessment of how well these aims had been fulfilled by the end of their house year.

\section{Subjects, methods, and results}

All graduates of Liverpool University Medical School qualifying in July 1985 (115) were sent a questionnaire in the last week of their preregistration year. Questions related to the adequacy of supervision, the teaching received, experience of common emergencies and procedures, and future career plans.

House officers were asked to indicate whether they considered themselves to be competent or unsure or had no experience of dealing with various common emergencies and of performing certain procedures. We received 105 replies $(91 \%), 61$ from men and 44 from women. Supervision was considered to be adequate by 99 respondents $(94 \%)$. Eighty nine respondents $(85 \%)$ received most of their teaching from other junior doctors, and only $47(45 \%)$ considered that they had learned a considerable amount from their consultants. Sixty five $(62 \%)$ had learned a lot from the nursing staff, and 53 doctors $(51 \%)$ had received little or no training in managing the terminally ill.

More than $95 \%$ considered themselves to be competent in dealing with acute left sided heart failure, acute asthma, pneumonia, haematemesis, and convulsions and diagnosing acute abdominal pain. Only 84 respondents

Walton Hospital, Liverpool L9 1AE

J E ELIZABETH, MB, MRCP, medical registrar

$S$ HUGHES, MB, MRCP, senior registrar in medicine

Correspondence to: Dr Hughes.
$(80 \%)$ considered themselves to be competent in dealing with a cardiac arrest. Although 101 (95\%) were competent in external cardiac massage and $87(83 \%)$ could maintain an airway, only $71(68 \%)$ knew how to use a defibrillator and only $37(35 \%)$ considered themselves to be competent in dealing with arrhythmias. Most doctors said that they were competent in performing chest aspiration, taking blood gases, setting up an intravenous infusion, and catheterising the urethra. Two thirds were confident in inserting a chest drain, doing a lumbar puncture, and performing abdominal paracentesis, but $13(11 \%)$ had never passed a nasogastric tube. Only nine doctors $(9 \%)$ were competent in inserting central venous lines, and none had experience of temporary cardiac pacing. Although all doctors had had experience of interviewing relatives, $20(19 \%)$ found it stressful.

Over $50 \%$ said that they would be working in hospital specialties in their next appointment. Although $77(73 \%)$ said that the preregistration year had had little or no effect on their career choice, $45(43 \%)$ said that they were less likely to take up hospital medicine and $23(22 \%)$ that they were more likely to do so as a result of their preregistration experience.

\section{Discussion}

Although the results of this survey are subjective, we believe that the respondents answered honestly, as indicated by the low levels of competence in performing central venous catheterisation and temporary cardiac pacing, procedures rarely undertaken by house officers. It is reassuring that most considered supervision to have been adequate. It is not surprising that house officers learnt most from other junior doctors, with whom they have most contact, but it is perhaps disappointing that less than half said that they had learnt a considerable amount from their consultants. Anecdotal reports suggest that training in terminal care is poor, and our results support this. Despite the Wilkes report's recommendation that a terminal care component should be included in undergraduate training $^{2}$ and a previous report on a terminal care teaching programme $\mathrm{m}^{3}$ there is still a need for improvement. The doctors in this study seemed more competent in performing cardiopulmonary resuscitation than those in other studies $^{4}$ but were still less competent in managing cardiac arrest than other emergency conditions. A programme for improving cardiopulmonary resuscitative skills has previously been suggested. ${ }^{5}$

One fifth of the respondents found interviewing relatives stressful. This duty is often delegated to the house officer, although it may be more appropriate for more senior doctors to undertake it, particularly in less clearcut cases. Career intentions did not seem to be greatly influenced by the preregistration year, although it is impossible to judge whether this is related to the trend towards making career choices earlier.

\section{References}

1 General Medical Council Education Committee. Recommendations on basic medical education. London: General Medical Council, 1980

2 Standing Medical Advisory Committee. Report of a working group on terminal care. London Department of Health and Social Security, 1980.

3 Irwin WG. Teaching terminal care at Queen's University of Belfast. II. Teaching arrangements and assessment of topic. Br Med f 1984;289:1604-5.

4 Skinner DV, Camm AJ, Miles S. Cardiopulmonary resuscitation skills of preregistration house officers. Br Med f 1985;290:1549-50.

5 Marsden AK, Redmond A, Tunstall Pedoe H, et al. Resuscitation needed for the curriculum? BrMed F 1985;290:1985.

(Accepted 13 October 1986) 